University of Nebraska - Lincoln

DigitalCommons@University of Nebraska - Lincoln

USDA Wildlife Services - Staff Publications

U.S. Department of Agriculture: Animal and Plant Health Inspection Service

February 2006

\title{
Accuracy of Aerial Telemetry Locations in Mountainous Terrain
}

\author{
Glen F. Gantz \\ Utah State University, Logan, UT \\ L. Charles Stoddart \\ Utah State University, Logan, UT \\ Frederick F. Knowlton \\ Utah State University, Logan, UT
}

Follow this and additional works at: https://digitalcommons.unl.edu/icwdm_usdanwrc

Part of the Environmental Sciences Commons

Gantz, Glen F.; Stoddart, L. Charles; and Knowlton, Frederick F., "Accuracy of Aerial Telemetry Locations in Mountainous Terrain" (2006). USDA Wildlife Services - Staff Publications. 504.

https://digitalcommons.unl.edu/icwdm_usdanwrc/504

This Article is brought to you for free and open access by the U.S. Department of Agriculture: Animal and Plant Health Inspection Service at DigitalCommons@University of Nebraska - Lincoln. It has been accepted for inclusion in USDA Wildlife Services - Staff Publications by an authorized administrator of DigitalCommons@University of Nebraska - Lincoln. 


\section{Accuracy of Aerial Telemetry Locations in Mountainous Terrain}

GLEN F. GANTZ, ${ }^{1}$ Department of Forest, Range, and Wildlife Sciences, Utah State University, Logan, UT 84322-5295, USA

L. ChARLES STODDART, ${ }^{2}$ United States Department of Agriculture, Wildlife Services, National Wildlife Research Center, Utah State University, Logan, UT 84322-5295, USA

FREDERICK F. KNOWLTON, ${ }^{3}$ United States Department of Agriculture, Wildlife Services, National Wildlife Research Center, Utah State University, Logan, UT 84322-5295, USA

(JOURNAL OF WILDLIFE MANAGEMENT 70(6):1809-1812; 2006)

\section{Key words}

accuracy, aerial telemetry, Bear River Mountains, location error, mountainous terrain, Utah.

Aerial telemetry is commonly used to locate wildlife in remote areas (Gilmer et al. 1981, White and Garrott 1990, Samuel and Fuller 1996). If locations are used to determine home range, habitat use, or similar parameters, error associated with locations must be estimated (Cederlund et al. 1979, Laundre et al. 1987, White and Garrott 1990, Carrel et al. 1997).

Typically, aerial locations are subject to 2 sources of error. If the transmitter-equipped animals are not sighted from the aircraft, their ground location must be estimated. Then, the estimated ground location must be identified on a map and recorded. The combined effect of both errors can be influenced by several variables including the relative sensitivity of the paired antennas, antenna mounting systems that can influence the radio signal, air turbulence, terrain, map quality, and observer experience and familiarity with the study area (Hoskinson 1976, Cochran 1980). When transmitter-equipped animals are visually located from the aircraft (Mech 1983), the first error source is eliminated. However, visual location is frequently hampered by ground cover, animal size, cryptic coloration or behavior of the animal, and constraints dictated by flight time or safety.

As pointed out by Leptich et al. (1994) and Carrel et al. (1997) the use of Loran-C or Global Positioning System (GPS) technology can help to reduce error associated with transferring locational data to maps, but objective estimates of aerial location error remain meager. Hoskinson (1976) determined minimum linear error of his aerial telemetry system after 10 trials to be $7 \mathrm{~m}$ and $40 \mathrm{~m}$, respectively, for 2 different pilots, and Whitehouse and Steven (1977) stated their aerial telemetry system was "capable of accuracy of the order of 200 m." However, neither procedures for measuring error nor the terrain types to which their estimates apply were described, nor is it clear whether the authors include errors associated with transferring estimated ground locations to maps. With regard to the latter, Leptich et al.

\footnotetext{
1 Present address: Richmond, UT 84333-1763, USA

2 Present address: Helena, MT 59602, USA

${ }^{3}$ E-mail: knowlton@cc.usu.edu
}

(1994) claimed a mean linear error of $49.9 \mathrm{~m}$ using GPS technology and $200.8 \mathrm{~m}$ mean error with LORAN-C technology. Carrel et al. (1997) compared the accuracy of estimated telemetry locations based on visual mapping with 5 types of electronic location assistance and discerned no difference in locational error among visual mapping, uncorrected GPS, and differentially corrected GPS technology. They reported linear error in the range of 73.1-80.7 $\mathrm{m}$ for all 3 procedures. We report the accuracy of visual mapping of aerial telemetry data collected during a test using transmitter collars in a montane environment.

\section{Study Area}

We conducted accuracy tests in the Bear River Mountain Range in northern Utah and southeastern Idaho, USA, during 3 flights in the first 2 weeks of September 1989. Elevations ranged from 1,425-3,042 m. Topography included steep mountains, deep, narrow canyons, high mountain valleys, and flats. Vegetative height varied, ranging from $<1 \mathrm{~m}$ on ridge tops and in montane parklands to $20 \mathrm{~m}$ in aspen groves and over $30 \mathrm{~m}$ in coniferous areas of north-facing slopes. At the time there was no snow cover and, although deciduous trees retained summer foliage, moisture levels were low. Schimpf et al. (1980) and Brough et al. (1987) provide further details of topography, vegetation, and climate.

\section{Methods}

We used the aerial telemetry system and transmitter locating procedures of Gantz (1990) and Gantz and Knowlton (2005) throughout the test. Briefly, we attached 3-element yagi antennas (design by Southwest Research Institute, San Antonio, Texas) aft of each wing strut on a Cessna 182 aircraft with the use of custom-made strut brackets. We mounted antennas with similar signal-to-noise attributes symmetrically with the main beams perpendicular to the fuselage, elements oriented vertically, and the front of the beam angled $8^{\circ}$ toward the ground. We routed coaxial leads from each antenna through air vents on the leading edge of each wing and connected them to a custom-made, solenoid- 
activated coaxial switch controlled by a toggle switch attached to the plane steering yoke. We coupled common output from the switch to a Telonics TR-2 receiver (Mesa, Arizona) operating in the $164-168 \mathrm{MHz}$ band. The observer received telemetry signals through a portable intercom (Sigtronics Transcom II, Covina, California) and David Clark H10-30 noise-attenuating headsets with microphones (Worcester, Massachusetts). The observer (principal investigator) was also the pilot and had 265 hours of radio-transmitter location experience prior to the test. Another qualified pilot was always on board for assistance and safety, as well as to control the plane while data were being recorded. We conducted the accuracy test only under good flying conditions. This was not a blind test because the observer-pilot knew a performance test was being conducted.

For the test, an assistant placed transmitters at selected locations within the study area and marked them on a United States Geological Survey (USGS) 7.5-minute topographic map with surface features used as references, with measured directions and paced distances from easily recognized map features such as stream junctions, rock outcrops, structures, etc. We used readily identifiable features to minimize error associated with the known locations. The assistant also classified each transmitter location as a canyon bottom, side hill, ridge, or flat. A canyon bottom was the lower half of a canyon where flight was restricted to 2 directions (up or down the canyon). We classified side hills as areas $>300 \mathrm{~m}$ below a ridge line where flight was restricted by a slope in only one direction, whereas ridges included areas less than $300 \mathrm{~m}$ below the crest of rugged terrain and flats had gradients $<20 \%$. Flight was not restricted in any direction on ridges and flats. To reduce aircraft travel time, the ground assistant notified the aerial observer of the general location (watershed) or direction from preceding transmitter, but no one in the plane knew the true location of the transmitter.

After acquiring a transmitter signal, the aerial observer identified its location by first aligning the plane toward the transmitter by listening alternately to signals from the left and right antennas and orienting the plane so the audio signals from the two antennas seemed equal. We maintained equal audio signal strengths from the 2 antennas by adjusting the plane heading while approaching the transmitter. We kept approach altitude as low as safely practical (10-300 m), dictated by topography, wind, turbulence, and pilot experience. We reduced receiver gain as we neared the transmitter to enhance sensitivity to the peak and identified passage over the transmitter by a pronounced peak in signal strength. If safely practical, we flew subsequent approaches from different directions as described by Mech (1983) and Knowlton (1995). The observer spent as much time, and made as many passes, as necessary to estimate the transmitter ground location or until he thought additional passes would not improve the precision of the location. We then recorded the estimated ground location (point) on a USGS 7.5-minute topographic map and used available topographic features as references. We also recorded the number of passes, time spent for each location estimate, and a prediction of the accuracy of the transmitter location estimate (very good, good, fair, and poor). Our prediction of location estimate quality was based on altitude above terrain, air turbulence, and the ease and altitude at which we could approach a transmitter.

We gained a secondary data set on aerial telemetry accuracy from a coyote movement study (Gantz 1990, Gantz and Knowlton 2005) in which instrumented animals were initially located via aerial telemetry and later determined to be dead. Similar to our accuracy test, we compared the aerial location estimates with the ground locations determined when the carcasses were recovered and plotted on a USGS 7.5-minute topographic map, but we did not record the attendant data related to flying time involved, number of passes made, or estimates of the quality of each aerial location.

Aerial location estimates (Universal Transverse Mercator [UTM] coordinates) were compared to known locations (UTM coordinates) with horizontal error for each measured to the nearest $10 \mathrm{~m}$. We assessed comparison of mean error differences among the 4 terrain types and the observer's prediction of accuracy with the estimated horizontal error with a 1-way analysis of variance (ANOVA) coupled with an a posteriori Tukey test (Zar 1974). We also used 1-way ANOVA to compare number of passes among terrain types and regression analysis to determine relationships between error and number of passes as well as total flight time.

\section{Results}

Mean horizontal error was $101 \mathrm{~m}(\mathrm{SE}=17, n=40)$. Although we calculated mean horizontal errors of $58 \mathrm{~m}$ (SE $=17), 48(\mathrm{SE}=26), 111(\mathrm{SE}=26)$, and $152(\mathrm{SE}=49)$ for

flat, ridge, side hill, and canyon locations, respectively, differences were not significant (Fig. 1). Number of passes per transmitter ranged from 3 to 7 and, among terrain types, varied little $(\bar{x}<1)$ and were not significantly different $(P=$ $0.23)$. We found no correlation between number of passes and error $(P=0.42)$, and observer prediction of transmitter location accuracy (Fig. 2) was correlated with horizontal error $\left(r^{2}=0.291, F_{3,36}=4.92, P=0.006\right)$. The Tukey test assigned the significance to differences between canyon and flat locations $(P=0.004)$, canyon and ridge locations $(P=$ $0.011)$, and marginally to canyon and side hill locations $(P=$ 0.064). The variation in our total flight times was small $(2.2-2.8 \mathrm{hr})$ and precluded meaningful assessment of effects of flight duration upon the accuracy of locations.

During the coyote movement study (Gantz 1990), 17 aerial locations were made of animals subsequently determined to be dead. When the carcasses were recovered, we noted a mean horizontal error of $275 \mathrm{~m}(\mathrm{SE}=77)$.

\section{Discussion}

Accuracy was generally poorest for transmitters located in canyons and on sidehills. In those situations we could make low-altitude approaches flying down canyons or along 


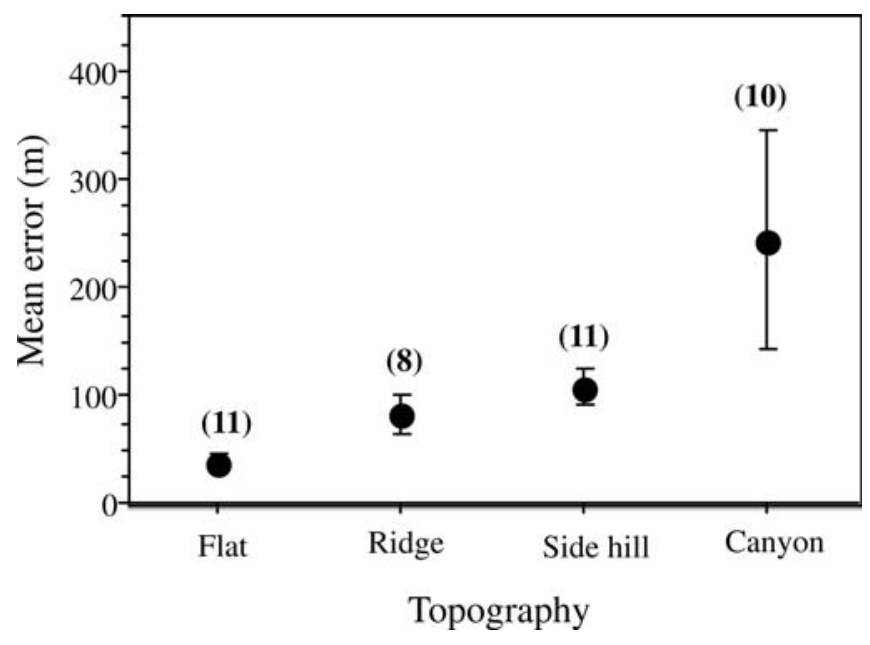

Figure 1. Distance errors for aerial telemetry location among 4 terrain types in the Bear River Mountains of northern Utah and southeastern Idaho, USA, 1989. Standard errors of the means are indicated.

sidehills, but approaches from other directions had to be flown at higher altitudes to clear ridges or hilltops. This was generally not a problem when transmitters were on flats or ridges. Signal reflection by terrain features also may have contributed to poor accuracy in canyons. Although we found no influence of total flight time on either horizontal error or amount of effort used to estimate a location, longer flight times could influence accuracy, particularly in turbulent or inclement weather.

We think our mean error of $101 \mathrm{~m}(\mathrm{SE}=17, n=40)$ was a good estimate of the maximum capability of our aerial telemetry system and observer under good conditions in mountainous terrain. It approaches the accuracy of $49.9 \mathrm{~m}$ reported for aerial GPS by Leptich et al. (1994) and 73.1$80.7 \mathrm{~m}$ for uncorrected GPS, differentially corrected GPS, and visual mapping procedures reported by Carrel et al. (1997). Although not statistically significant, locations tended to be more accurate amid less stringent flying situations (Fig. 1). It is also relevant that the pilot-observer was generally aware of the relative precision associated with individual locations, information that could be used to censure locations during specific analyses.

During a preliminary test of the accuracy of our aerial telemetry procedures, conducted in December 1987, the observer had only 12-17 hours of aerial telemetry, mountain flying, and Cessna experience. Mean error for that initial trial was $214 \mathrm{~m}(\mathrm{SE}=38, n=12)$. The improved performance observed during the more recent accuracy test was after 250 additional hours of experience locating transmitters in mountainous terrain. This supports Hoskinson's (1976) and Cochran's (1980) conclusions that experience is important in accurately locating transmitters. Because the observer knew he was being tested, evaluation apprehension (Rosenberg 1969, Balph and Balph 1983, Balph and Romesburg 1986, Mills and Knowlton 1989) may have affected performance during both the initial trial and the accuracy test. Mean error associated with the recovery of dead coyotes $(275 \mathrm{~m})$ may provide a more

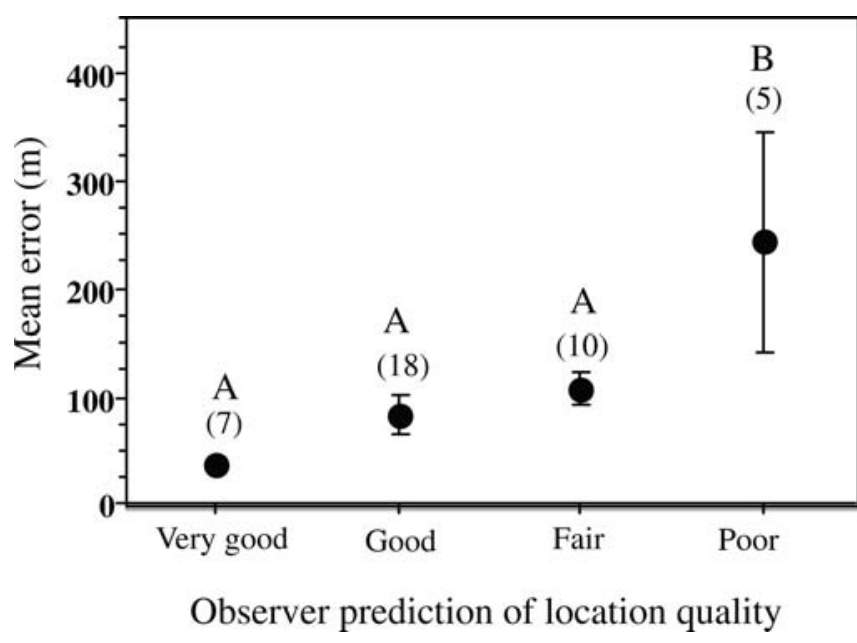

Figure 2. Comparison of aerial telemetry distance errors in relation to observer-pilot prediction of location accuracy for test transmitters located in the Bear River Mountains of northern Utah and southeastern Idaho, USA, 1989. Standard errors of the means are indicated. Estimates labeled with similar letters are not statistically different $(P=$ 0.05).

realistic estimate of the error encountered in routine operations, although in our case, other variables may also have contributed to this estimate.

We made no attempt to partition aerial location error into error associated with ground location estimates and error associated with recording those estimates. However, we think the observer's ability to transfer a ground location estimate to a topographic map did not change between the initial trial and the accuracy test, and we speculate the difference in errors between the 2 trials resulted from improvement in estimating transmitter ground locations. Although the observer became more familiar with the study area during 250 hours flying in the study area, he did not become more familiar with topographic features near transmitter locations because transmitter locations were changed frequently. Recent developments in use of GPS technology (Leptich et al. 1994, Carrel et al. 1997) undoubtedly can help reduce error associated with transferring estimated transmitter locations to map points.

The mean error determined during the coyote movement study differed in several ways from the initial trial and the accuracy test. Observer experience was variable because data were collected throughout a 2.5-year study period. Evaluation apprehension was absent because the observer was not aware locations would be used to estimate accuracy and less care may have been taken with these estimates (Mills and Knowlton 1989). Additionally, ground locations when the dead coyotes were retrieved may not have been documented as precisely as transmitters during the accuracy test.

Weather conditions were also more variable during the coyote movement study than during the initial trial and the accuracy test. We often estimated coyote locations when conditions were less than ideal because of pre-arranged flight schedules, with most data acquired in January and February when air turbulence and general weather con- 
ditions were more severe. Such conditions often require making passes at higher altitudes $(>200 \mathrm{~m}$ above ground level), thus increasing potential for error. These factors likely interacted to increase mean error during the coyote movement study compared to the other 2 tests. However, the coyote movement study mean error may more closely represent error to be expected under routine operations.

\section{Management Implications}

Radiotelemetry is useful for gathering data for wildlife research and management purposes. However, interpretations should be constrained within the accuracy and precision of the equipment and personnel involved in collecting the data. In mountainous areas, precision and accuracy are typically sacrificed in the interest of maintaining safe flying conditions. In our case, errors were 2-3 times larger for canyon and hillside locations compared to flat and ridge-top situations. Personnel should test the accuracy and precision of radiotelemetry in their specific application(s),

\section{Literature Cited}

Balph, D. F., and M. H. Balph. 1983. On the psychology of watching birds: the problem of observer-expectancy bias. Auk 100:755-757.

Balph, D. F., and H. C. Romesburg. 1986. The possible impact of observer bias on some avian research. Auk 103:831-832.

Brough, R. C., D. L. Jones, and D. J. Stevens. 1987. Utah's Comprehensive Weather Almanac. Publishers, Salt Lake City, Utah, USA.

Carrel, W. K., R. A. Ockenfels, J. A. Wennerlund, and J. C. Devos Jr. 1997. Topographic mapping, Loran-C, and GPS accuracy for aerial telemetry locations. Journal of Wildlife Management 61:1406-1412.

Cederlund, G., T. Dreyfert, and P. A. Lemnell. 1979. Radio-tracking techniques and the reliability of systems used for larger birds and mammals. Swedish Environmental Protection Board, Solna, Sweden.

Cochran, W. W. 1980. Wildlife telemetry. Pages 507-520 in S. D. Schemnitz, editor. Wildlife management techniques manual. Fourth edition. The Wildlife Society, Washington, D.C., USA.

Gantz, G. F. 1990. Seasonal movement patterns of coyotes in the Bear River Mountains of Utah and Idaho. Thesis, Utah State University, Logan, USA.

Gantz, G. F., and F. F. Knowlton. 2005. Seasonal activity areas of coyotes in the Bear River Mountains of Utah and Idaho. Journal of Wildlife Management 69:1652-1659.

Gilmer, D. S., L. M. Cowardin, R. L. Duval, L. M. Mechlin, C. W. Shaiffer, and V. B. Kuechle. 1981. Procedures for the use of aircraft in wildlife biotelemetry studies. United States Fish and Wildlife Service Resource Publication 140, Washington, D.C., USA.

Hoskinson, R. L. 1976. The effect of different pilots on aerial telemetry error. Journal of Wildlife Management 40:137-139.

Knowlton, F. F. 1995. Radio telemetry as a wildlife research tool. Pages 81-106 in S. H. Berwick and V. B. Saharia, editors. The development of international principles and practices of wildlife research and preferably in blind-test situations. Where this is not practical, locational errors in operational programs may be twice as great as inferred directly from the tests. Interpretations should not exceed the capabilities of the datacollection process.

\section{Acknowledgments}

Our study was supported by the National Wildlife Research Center of the Animal and Plant Health Inspection Service within the United States Department of Agriculture. Logan Air Service assisted in complying with Federal Aviation Administration requirements and provided copilots. Special thanks to R. Cutler for statistical advice. Comments and suggestions from R. J. Burns, M. R. Conover, W. Kasworm, L. D. Mech, C. Servheen, J. A. Shivik, T. Thier, G. C. White, L. A. Windberg, as well as the editorial staff for the Wildlife Society Bulletin and the Journal of Wildlife Management, helped to improve various drafts of this manuscript.

management: Asian and American approaches. Oxford University, Delhi, India.

Laundre, J. W., R. D. Reynolds, S. T. Knick, and I. J. Ball. 1987. Accuracy of daily point relocations in assessing real movement of radio-marked animals. Journal of Wildlife Management 51:937-940.

Leptich, D. J., D. G. Beck, and D. E. Beaver. 1994. Aircraft-based LORAN-C and GPS accuracy for wildlife research on inland study sites. Wildlife Society Bulletin 22:561-565.

Mech, L. D. 1983. Handbook of animal radio-tracking. University of Minnesota, Minneapolis, USA.

Mills, L. S., and F. F. Knowlton. 1989. Observer performance in known and blind radio-telemetry accuracy tests. Journal of Wildlife Management 53:340-342.

Rosenberg, M. J. 1969. The conditions and consequences of evaluation apprehension. Pages 279-349 in R. Rosenthal and R. L. Rosnow, editors. Artifacts in behavioral research. Academic, New York, New York, USA.

Samuel, M. D., and M. R. Fuller. 1996. Wildlife radiotelemetry. Pages 370-418 in T. A. Bookout, editor. Research and management techniques for wildlife and habitats. Fifth edition, revised. The Wildlife Society, Bethesda, Maryland, USA.

Schimpf, D. J., J. A. Henderson, and J. A. MacMahon. 1980. Some aspects of succession in the spruce-fir forest zone of northern Utah. Great Basin Naturalist 40:1-25.

White, G. C., and R. A. Garrott. 1990. Analysis of wildlife radio-tracking data. Academic, San Diego, California, USA.

Whitehouse, S., and D. Steven. 1977. A technique for aerial radio tracking. Journal of Wildlife Management 41:771-775.

Zar, J. H. 1974. Biostatistical analysis. Third edition. Prentice-Hall, Upper Saddle River, New Jersey.

Associate Editor: Carroll. 